\title{
Ischaemic infarct of the brain stem combined with bisymptomatic Klippel-Trénaunay-Weber syndrome and cutis laxa
}

\author{
E. A L B E R T I ${ }^{1}$ \\ From the Neurological Clinic, Heidelberg University, Heidelberg, W. Germany
}

SYNOPSIS The combination of Klippel-Trénaunay-Weber syndrome (KTWS) with intracranial vascular malformations is documented by angiography in a 25 year old man with the classical features of KTWS: systematized naevi, hypertrophy of the right side, and varicosis. In addition, the syndrome was associated with 'cutis laxa', a coincidence of some rarity. The patient suffered from an ischaemic infarct of the brain stem with several neurological deficits.

In 1900, Klippel and Trénaunay described a triad of symptoms consisting of a naevus telangiectaticus in metameric distribution affecting the entire lower extremity, unilateral varicectasia, and hypertrophy of the affected side (unilateral macrosomia).

In combination with the syndrome described above, Parkes Weber in 1918 observed arteriovenous deformities occurring in addition to varicectatic changes. Therefore, this clinical entity is now generally called the Klippel-Trénaunay-Parkes-Weber syndrome (KTPWS). Other synonyms are: naevus osteohypertrophicus, macrosomia, angiomatosis osteohypertrophica, haemangiectasia hypertrophicans, telangiectasia and angioelephantiasis, angioplastic macrosomia, angio-osteo-hypertrophic syndrome, phlébectasies ou phlébartériectasies étendues congénitales complexes (Kramer, 1972).

In 1953, Fegeler et al. differentiated between the three cardinal symptoms, systematized haemangiomas, hypertrophy, and varicosis, and the secondary symptoms which include changes in the peripheral nervous system such as perception and vegetative disorders. Epileptic fits, changes in the electroencephalogram,

\footnotetext{
${ }^{1}$ Address for correspondence: Dr. E. Alberti, 6900 Heidelberg (FRG) Vosstr. 2, Neurological Clinic, University of Heidelberg, Heidelberg. (Accepted 2 February 1976.)
}

or oligophrenia have been described in this context only very infrequently (André, 1973).

This paper describes a rare combination of the Klippel-Trénaunay-Parkes-Weber syndrome with 'cutis laxa' and intracranial vascular deformities leading to the clinical picture of an ischaemic infarct of the brain stem. The author believes that this is the first description of a clinical course of this kind.

\section{CASE HISTORY}

The patient K.B., aged 25 years, was admitted on 3 March 1974 and discharged home on 20 April 1974.

There was no history of previous serious illness. The patient had performed hard physical work for eight years. Headaches, limited to the occipital region for three days, started eight days before admission. After four days without complaint, the patient woke up with splitting headache; vomiting occurred some hours later. This had been preceded by particularly strenuous work the day before. One day later, the patient complained of dryness in the mouth and continuing occipital headache, later followed by a sensation of numbness in the legs spreading to the upper extremities. The patient was admitted for treatment.

NEUROLOGICAL FINDINGS ON ADMISSION The patient had to be supported on both sides when walking. There was an ataxic gait, predomin- 
antly of the right leg, sensorimotor proportional hemiparesis of the right side and impaired coordination of the right. There was anisocoria (left pupil more dilated than right pupil); paralysis of the right 6 th cranial nerve, dysadaptation and course and jerking end position nystagmus in both eyes. There was also nuclear paresis of the left facial nerve, strangled voice, paralysis of deglutition and profuse salivation. Slight drowsiness was noted. During physical examination of the patient it was found that dermatomes C4-T4 and $\mathrm{S} 1 / \mathrm{S} 2$ on the right side of the body showed several palm-sized naevi telangiectatici, whereas on the left side, at T6 and T11, only two naevi telangiectatici were located, each one being the size of a shilling. The right side of the body was hypertrophied, the difference in circumference of the extremities varying from 1 to $2 \mathrm{~cm}$. This was particularly obvious in the right hallux. Moderate varicosis was present in the right foot and small herniae in the fatty tissue of the heels. The skin, predominantly on the right-hand side of the body, was found to be excessively elastic and the joints of the same side were slightly hyperextensible.

\section{ADDITIONAL FINDINGS A chest radiograph was}

normal. A film of the pelvic region showed phleboliths located in the minor pelvis. The lowest lumbar vertebra was partially united with the os sacrum on the right side. Radiography of both hands showed asymmetry due to macrosomia of the right hand. An EEG was normal. Lumbar puncture yielded CSF containing 11-3 cells per $\mathrm{mm}^{3}$, albumin level was normal. Laboratory findings were within normal limits.

ARTERIOGRAPHY Retrograde arteriography of the left brachial artery revealed subnormal diameter of the left vertebral artery which supplied exclusively the left inferior cerebellar artery.

A percutaneous arteriogram of the left carotid artery showed a wide-arched course of the thalamostriate vein.

A retrograde arteriogram of the right brachial artery (Fig. 1) showed aneurysmal dilatation of the terminal part of the basilar artery, and ectasis at the junction of the right vertebral artery (which was of wide diameter) and the basilar artery. Vascular abundance of the superior cerebellar artery was noticeable.

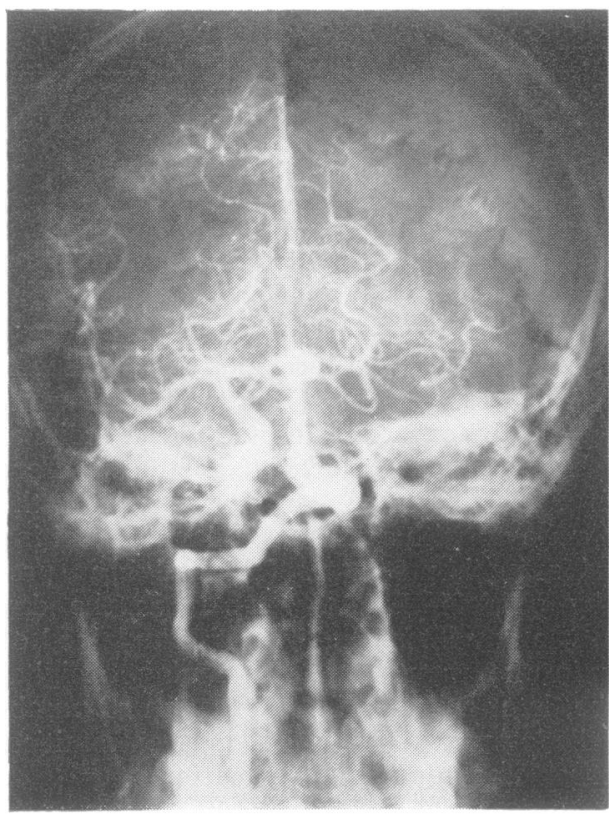

(a)

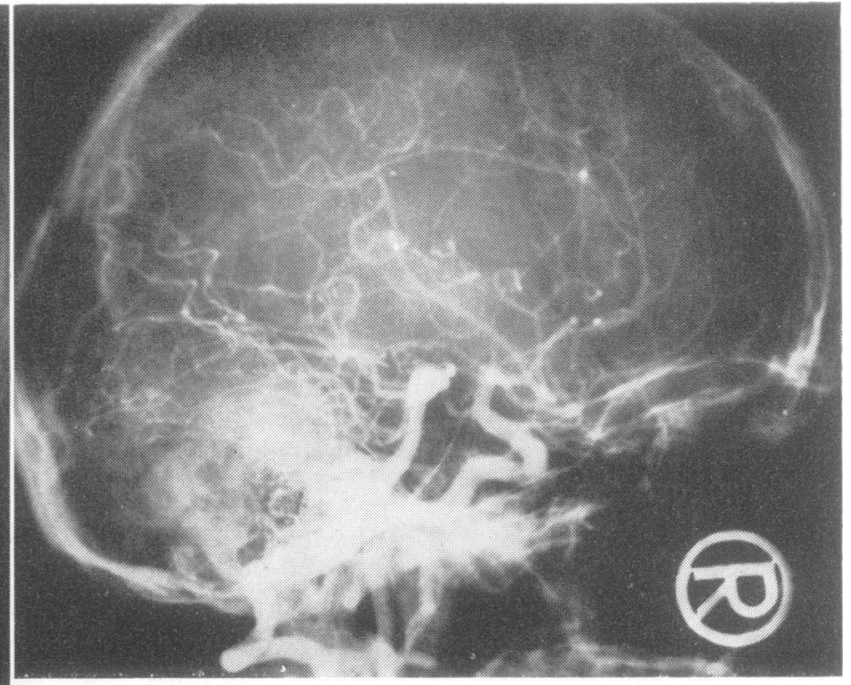

(b)

FIG. 1. Retrograde arteriogram of the right brachial artery. (a) AP view. (b) Lateral view. 
PROGRESS Some days after the attack the patient was able to swallow again. His dexterity, which at first had been most adversely affected on the right side of the body, improved as well. After one month there was still a noticeably ataxic gait, an obstinate nystagmus, and recurrent attacks of headache. On discharge from hospital the patient still showed ataxia on the right, vertical spontaneous nystagmus, and nystagmus on deviation of the eyes. Pupillary reaction on convergence was sluggish. At the follow-up examination five months later the patient still complained of clumsiness on the right side, and of blurred vision when turning his head or when looking sideways. His speech continued to return to normal. One year after the attack there was still evidence of spontaneous nystagmus with a rotatory component, and of paralysis of the right 6th nerve, with the soft palate sagging on the left, comparatively feeble gag reflex on the left, deviation of the protruded tongue to the left, sluggish pupillary reaction, and some remaining signs of ataxia on the right side. Eighteen months after the infarct the patient complains of sporadic headaches limited to the occipital region and of 'blurred pictures' when walking. There is still evidence of spontaneous nystagmus with a rotatory and a vertical component and of nystagmus on deviation of the eyes caused by a slight residual paralysis of the right 6 th nerve. The right side of the body shows increased tendon reflexes, whereas the abdominal reflex is absent. Co-ordination of the right side of the body is still clearly impaired.

\section{DISCUSSION}

In 1954, Burke et al., in their discussion of disseminated haemangiomatosis, stated that the existence of such vascular deformities should give rise to the consideration that they might occur together with intracranial angiomatous malformations. Cases of KTPWS coinciding with such disturbances of the vascular system supplying blood to the CNS have relatively rarely been described in the literature. Den Hartog Jager (1949) reported on a venous angioma in the spinal region, and Krayenbühl et al. (1970) reported an atrioventricular fistula located in the thoracic part of the spine which led to compression of the spinal cord. Brüning (1956) discovered cases of angiomatosis in the diencephalon, in the medulla oblongata, and in the spinal cord; Thierbach and Hübner (1964) described angiomatosis and regressive changes mainly in the lower brain stem and in the cerebellum of a 20 year old patient. Haberland and Perou (1966) reported on venous angiomatosis of the skull vault. In 1968, Avasthey and Roy described cases of arteriovenous deformities in the cerebrum.

A considerable number of cases of KTPWS are combined with phacomatoses, the latter sometimes necessarily involving vascular deformations in the area of the CNS: SturgeWeber syndrome (Laxenaire, 1961); Von Hippel-Lindau syndrome (Den Hartog Jager, 1949); tuberous sclerosis (Laxenaire, 1961; Troost et al., 1975); multiple neurofibromatosis or Recklinghausen's disease (Laxenaire, 1961). Schnyder et al. (1956) compiled the interrelations between some of the syndromes (Fig. 2). The case of KTPWS described by the author in this paper is to be deemed bisymptomatic because the varicosis component of the triad (cutaneous symptoms, naevi, osteohypertrophy, and vascular symptoms) is rather imperfectly developed. Arterial thromboses show a marked inclination to develop in vascular anomalies located in the cerebrobasilar circulatory system. This may evolve into a secondary embolism and a consecutive ischaemic infarct within this vascular region. The protracted clinical course of the case described here supports the assumption that this infarct was caused by a thrombotic process. Clinical examination yielded no evidence of heart disease or of inflammatory disease. In view of the age of the patient, however, the thrombocyte aggregation test must be considered pathological. It is probable that the brain stem infarct caused an extensive lesion affecting the lower portion of the pons and the medulla oblongata. This case also presents an unusual feature by combining KTPWS with intracranial vascular deformities and cutis laxa. The only other case of a similarly diffuse dystrophy of the elastic tissue was reported by Thiers et al. (1964) in a 6 year old child. In this case disturbance of tissue metabolism was evidenced by increased diuresis of acid mucoproteins. 


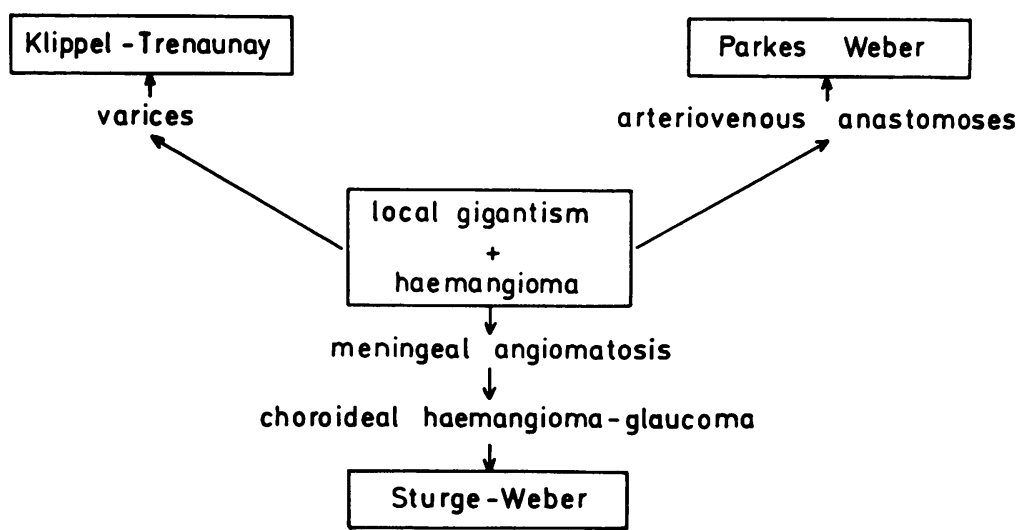

FIG. 2 Interrelation of Klippel-Trénaunay, Parkes Weber, and Sturge-Weber syndrome (Schnyder et al., 1956).

Cutis laxa may be either of a general nature or segmentally restricted. A mesenchymal dysplasia of this kind is presented in its fully developed state by the Ehlers-Danlos syndrome, combining fragility and hyperelasticity of the skin (note: the skin was not fragile in our case), hyper-extension of the joints, and changes in the eyes and blood vessels. This syndrome may also combine with KTPWS (Lynch et al., 1965; Servelle, 1962), leading to the conclusion that any appreciable deficiency in the tissue metabolism may constitute an additional factor causing the development of certain symptoms such as vascular deformations and changes in the cutaneous structure. There are many primary defects which may lead to the above symptoms. The EhlersDanlos syndrome, for instance, is caused by a disturbance in the formation of the collagenous dystrophy, and osteogenesis imperfecta by an impaired maturation of collagen. The Pfaundler-Hurler syndrome involves a qualitatively and quantitatively abnormal formation of mucopolysaccharides or structural polysaccharides, and Marfan's syndrome consists of a complex deficiency phenomenon in the connective tissue (McKusick, 1959; Deckers, 1965; Laitinen et al., 1966; Alberti, 1970).

We may, therefore, conclude that hereditary factors disturbing the tissue metabolism may be of some relevance in symptom combinations similar to the case described in this paper. On the other hand, the presence of angiomatous and structural changes of the skin, especially in coincidence with neurological symptoms, may indicate that the structure of intracranial and spinal arterieso and veins has been affected. The coincidence ${ }_{0}$ of KTPWS, cutis laxa, and intracraniaP vascular deformities is rare.

\section{REFERENCES}

Alberti, E. (1970). Das Marfan-Syndrom. Thesis Heidelberg.

André, J. M. (1973). Syndrome de Klippel-TrénaunayWeber. 'Dysplasies veineuses congénitales'. In Les Dysplasies Vasculaires Systématisées, pp. 179-189. Expansion Scientifique Française: Paris.

Avasthey, P., and Roy, S. B. (1968). Primary pulmonary hypertension, cerebrovascular malformation and lymphoedema feet in a family. British Heart Journal, 30, 769-775.

Brüning, E. J. (1956). Zur Pathologie des KlippelTrénaunayschen Syndroms (partieller Riesenwuchs mit planen Angiomen). Zentralblatt der allgemeinen Pathologie und pathologischen Anatomie, 95, 142-151.

Burke, E. C., Winkelmann, R. K., and Strickland, M. K. (1954). Disseminating hemangiomatosis. American Journal of Diseases of Children, 108, 418-424.

Deckers, P. F. L. (1965). Biochemische afwijkingen bij het syndroom van Marfan (arachnodactylie). Nederlands Tijdschrift voor Geneeskunde, 109, 820-822.

Den Hartog Jager, W. A. (1949). About two new forms in the group of the phacomatoses. Folia Psychiatrica, Neurologica et Neurochirurgica Neederlandica, 52, 356-364. 
Fegeler, F., Holtschmidt, J., and Kohrs, S. (1953). Die Beziehungen des Klippel-Trénaunay-Weber Syndroms zum partiellen Riesenwuchs. Archiv für Dermatologie und Syphilis, 195, 402-433.

Haberland, C., and Perou, M. (1966). Bone involvement in Sturge-Weber-Dimitri syndrome. Confinia Neurologica, 28, 413-422.

Klippel, M., and Trénaunay, R. (1900). Du naevus variqueux osteohypertrophique. Archives Générales de Médecine, 185, 641-672.

Kramer, W. (1972). Klippel-Trénaunay syndrome. In Handbook of Clinical Neurology, vol. 14, pp. 390 404. Edited by P. J. Vinken and G. W. Bruyn. North-Holland: Amsterdam.

Krayenbühl, H., Benini, A., Bollinger, A., Wellauer, J., and Senning, A. (1970). Ein Fall von KlippelTrénaunay-Weber Syndrom mit arteriovenöser Fistel im Bereich der Brustwirbelsäule und Rükenmarkskompression. Neurochirurgica (Stutt), 13, 228-231.

Laitinen, O., Nikkila, E. A., and Kivirikko, K. I. (1966). Hydroxyproline in the serum and urine. Normal values and clinical significance. Acta Medica Scandinavica, 179, 275-284.

Laxenaire, M. (1961). Les Gigantismes Partiels. Doin: Paris.

Lynch, M. T., Larsen, A. L., Wilson, R., and
Magnuson, C. L. (1965). Ehlers-Danlos syndrome and 'congenital' arterio-venous fistulae. A clinicopathologic study of a family. Journal of the American Medical Association, 194, 1011-1014.

McKusick, V. A. (1959). Vererbbare Störungen des Bindegewebes. Thieme: Stuttgart.

Parkes Weber, F. (1918). Haemangiectatic hypertrophy of limbs. British Journal of Children's Diseases, 15, 13-23.

Schnyder, U. W., Landolt, E., and Martz, G. (1956). Syndrome de Klippel-Trénaunay avec irien atypique. Journal de Génétique Humaine, 5, 1-8.

Servelle, M. (1962). Edémes Chroniques des Membres chez l'Adulte et chez l'Enfant, p. 382. Masson: Paris.

Thierbach, R., and Hübner, K. (1964). Beitrag zum Klippel-Trénaunay-Weber Syndrom. Acta Neurochirurgica (Wien), 12, 52-68.

Thiers, Mm. H., Colomb, D., Fayolle, J., Cuffia, Ch., Picot, C., and Descos, L. (1964). Syndrome de Klippel-Trénaunay associé á une dystrophie diffuse du tissu élastique. Bulletin de la Société Française de Dermatologie et de Syphiligraphie, 71, 617-618.

Troost, B. T., Savino, P. J., and Lozito, J. C. (1975). Tuberous sclerosis and Klippel-Trénaunay-Weber syndromes. Journal of Neurology, Neurosurgery, and Psychiatry, 38, 500-504. 